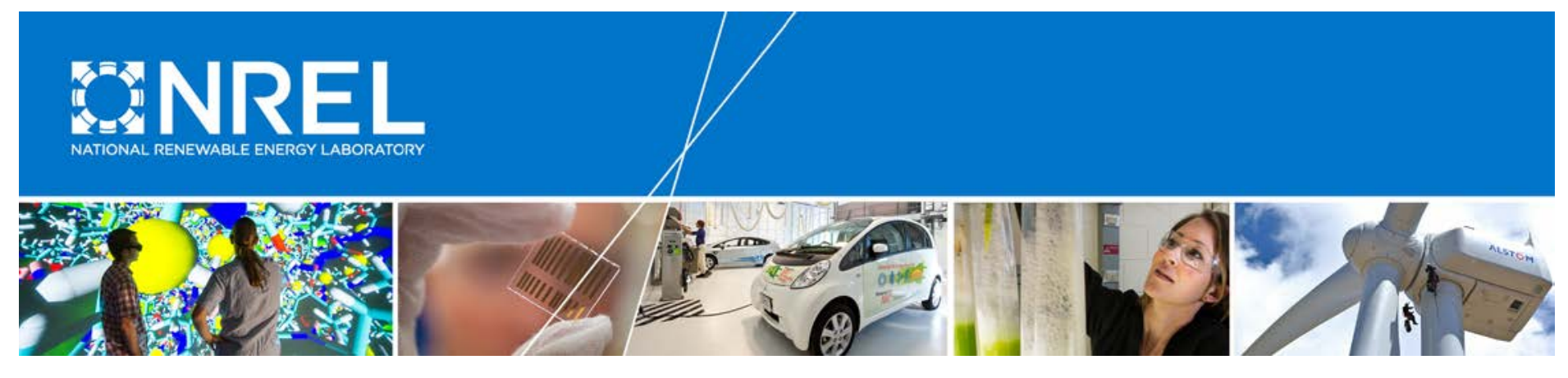

\title{
Frequency Support of PMSG- WTG Based on Improved Inertial Control
}

\section{Preprint}

Z. Wu, X. Wang, and W. Gao

University of Denver

M. Kang, M. Hwang, and Y. Kang

Chonbuk National University

V. Gevorgian and E. Muljadi

National Renewable Energy Laboratory

To be presented at the 2016 IEEE Power and Energy Society General Meeting

Boston, Massachusetts

July 17-21, 2016

NREL is a national laboratory of the U.S. Department of Energy Office of Energy Efficiency \& Renewable Energy Operated by the Alliance for Sustainable Energy, LLC

This report is available at no cost from the National Renewable Energy Laboratory (NREL) at www.nrel.gov/publications.

\section{Conference Paper}

NREL/CP-5D00-65916

March 2016 


\section{NOTICE}

The submitted manuscript has been offered by an employee of the Alliance for Sustainable Energy, LLC (Alliance), a contractor of the US Government under Contract No. DE-AC36-08GO28308. Accordingly, the US Government and Alliance retain a nonexclusive royalty-free license to publish or reproduce the published form of this contribution, or allow others to do so, for US Government purposes.

This report was prepared as an account of work sponsored by an agency of the United States government. Neither the United States government nor any agency thereof, nor any of their employees, makes any warranty, express or implied, or assumes any legal liability or responsibility for the accuracy, completeness, or usefulness of any information, apparatus, product, or process disclosed, or represents that its use would not infringe privately owned rights. Reference herein to any specific commercial product, process, or service by trade name, trademark, manufacturer, or otherwise does not necessarily constitute or imply its endorsement, recommendation, or favoring by the United States government or any agency thereof. The views and opinions of authors expressed herein do not necessarily state or reflect those of the United States government or any agency thereof.

This report is available at no cost from the National Renewable Energy Laboratory (NREL) at www.nrel.gov/publications.

Available electronically at SciTech Connect http:/www.osti.gov/scitech

Available for a processing fee to U.S. Department of Energy and its contractors, in paper, from:

U.S. Department of Energy

Office of Scientific and Technical Information

P.O. Box 62

Oak Ridge, TN 37831-0062

OSTI http://www.osti.gov

Phone: 865.576.8401

Fax: 865.576.5728

Email: reports@osti.gov

Available for sale to the public, in paper, from:

U.S. Department of Commerce

National Technical Information Service

5301 Shawnee Road

Alexandria, VA 22312

NTIS http://www.ntis.gov

Phone: 800.553 .6847 or 703.605 .6000

Fax: 703.605.6900

Email: orders@ntis.gov 


\section{Frequency Support of PMSG-WTG Based on Improved Inertial Control}

\author{
Z. Wu, Student Member, IEEE \\ X. Wang, Student Member, IEEE \\ W. Gao, Senior Member, IEEE \\ Univ. of Denver \\ wzpbsb@du.edu \\ Wenzhong.gao@du.edu \\ wangxiao.owl@gmail.com
}

\author{
M. Kang, Student Member, IEEE \\ M. Hwang, Student Member, IEEE \\ Y. Kang, Senior Member, IEEE \\ Chonbuk National Univ., Korea \\ bass0680@jbnu.ac.kr \\ skyway333@jbnu.ac.kr. \\ yckang@jbnu.ac.kr
}

\author{
V. Gevorgian, Member, IEEE \\ E. Muljadi, Fellow, IEEE \\ National Renewable Energy Laboratory \\ vahan.gevorgian@nrel.gov \\ eduard.muljadi@nrel.gov
}

\begin{abstract}
With increasing integrations of large-scale systems based on permanent magnet synchronous generator wind turbine generators (PMSG-WTGs), the overall inertial response of a power system will tend to deteriorate as a result of the decoupling of rotor speed and grid frequency through the power converter as well as the scheduled retirement of conventional synchronous generators. Thus, PMSG-WTGs can provide value to an electric grid by contributing to the system's inertial response by utilizing the inherent kinetic energy stored in their rotating masses and fast power control. In this work, an improved inertial control method based on the maximum power point tracking operation curve is introduced to enhance the overall frequency support capability of PMSG-WTGs in the case of large supply-demand imbalances. Moreover, this method is implemented in the CART2-PMSG integrated model in MATLAB/Simulink to investigate its impact on the wind turbine's structural loads during the inertial response process. Simulation results indicate that the proposed method can effectively reduce the frequency nadir, arrest the rate of change of frequency and mitigate the secondary frequency drop while imposing no negative impact on the major mechanical components of the wind turbine.
\end{abstract}

Index Terms-Inertial response, permanent magnet synchronous generator wind turbine, FAST model, frequency regulation, maximum power point tracking.

\section{INTRODUCTION}

$\mathrm{N}$ owadays, a high penetration of variable-speed wind turbine generators (VSWTGs) based on permanent magnet synchronous generators (PMSGs) and doubly-fed induction generators (DFIGs) may cause a decline in grid frequency response due to the lower inertia and decreased droop response from conventional synchronous generators because they are gradually being replaced or decommitted [1]. However, PMSGs inherently possess a significant amount of kinetic energy stored in the rotating mass of their turbine blades and gearbox, and this can be employed to strengthen the total inertia of a power system through fast and flexible power converter control. Moreover, fully decoupling the rotor speed from the grid frequency allows PMSGs to remain in stable operation and rapidly respond to grid frequency variations in any severe frequency event. Compared to DFIGs that have identical rated capabilities and an inertial constant, PMSGs are able to provide a larger inertial response by using their full power converter, which allows for a wider range of rotor speed (0.2 p.u-1.2 p.u) [2], [3]. Therefore, it is valuable to the grid to fulfill the potential capability of PMSG-WTGs in supporting system frequency regulation.

Until now, three major types of inertial controls enabled VSWTGs to realize emulated inertial response: natural inertial control, constant inertial control, and virtual inertial control [2]-[8]. Natural inertial control is based on the rate of change of frequency (ROCOF) df/dt to provide inertial response [2][6]. Constant inertial response is defined as a certain amount of constant active power released from kinetic energy, and it sustains for a couple of seconds [2], [7]. Virtual inertial control is to adjust the active power output of a VSWTG based on the system frequency deviation to contribute to the system's inertial response [8].

In this paper, the maximum power point tracking (MPPT)oriented inertial control is designed for a PMSG-WTG without relying on the ROCOF measurement and power reserve. It comprises mainly three stages of inertial response, temporary deloaded operation, and rotor speed recovery. Meanwhile, a complete CART2-PMSG integrated model is developed as a platform using MATLAB/Simulink to investigate the impact of the proposed inertial response on the wind turbine's structural and component loads. In addition, the performance of the dynamic frequency regulation using the proposed method is evaluated in case of one generator trip.

\section{CART2 TEST BED AND SIMULINK MODEL}

\section{A. CART2 Test Bed}

The Controls Advanced Research Turbine (CART) is a twobladed, teetered, upwind, active-yaw wind turbine located at the National Wind Technology Center (NWTC) of the National Renewable Energy Laboratory (NREL). It serves as a test bed for various aspects of advanced control schemes for medium- to large-scale machines. It is a variable-speed, Type 4 wind turbine equipped with a full-scale power converter [9]. Each blade can be independently pitched through its own electromechanical servo system. Two types of generators are available in CART: a synchronous generator and a squirrelcage induction generator. These make it possible to control the torque from minus rating $\left(-\tau_{\text {rated }}\right.$, motoring) to plus rating $\left(+\tau_{\text {rated }}\right.$, generating) at an acceptable range of the rotor speed. Power electronics are utilized to command the specified generator torque, and the full-span blade pitch controls the rotor speed. The rated electrical power is $600 \mathrm{~kW}$ at a lowspeed shaft speed of $48.32 \mathrm{rpm}$, and it is maintained in Region 3 using a conventional variable-speed approach.

\section{B. CART2 Simulink Model}

To simulate the characteristics of the CART2 test bed before the field test is carried out, a CART2 model is developed in MATLAB/Simulink based on the Fatigue, 
Aerodynamics, Structures, and Turbulence (FAST) module [10]. It incorporates a simplified generator model, yaw controller, and pitch angle controller. Fig. 1 shows a typical relationship among FAST, the generator model, pitch controller, and yaw controller. Fig. 2 illustrates four regions wherein the wind power generator safely and efficiently operates under different wind speed conditions. In Region 1, the wind turbine stays in a stall state due to the low wind speed. In Region 2, the wind turbine runs in MPPT mode when the tip speed ratio (TSR) is maintained constant at the optimal value to maximize the wind energy capture through the generator torque control. At the same time, the blade pitch is held constant at its run-pitch value (-1 degree). In Region 2.5 , the rotor speed starts at a value lower than the rated value and gradually reaches the rated torque at the rated speed or slightly below it. In this way, a smooth transition is achieved from Region 2 to Region 3. In Region 3, the generator torque remains constant at the rated value, and the pitch angle controller is activated under the high wind speed condition to restrict the rotor speed below the rated value [10], [12].

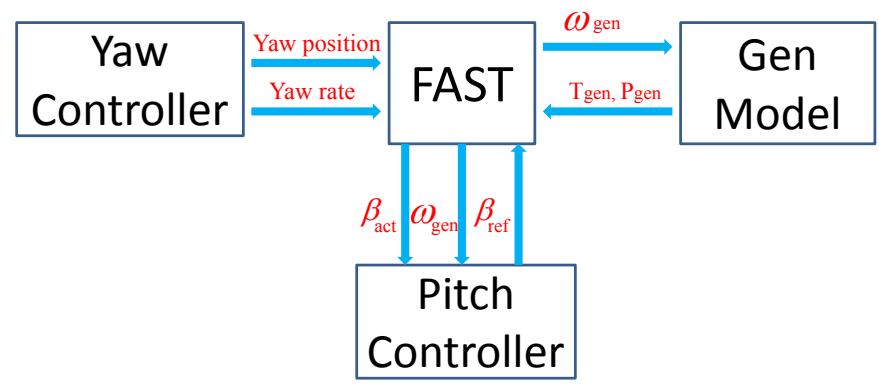

Fig. 1. Simple flowchart of the CART2 baseline Simulink model

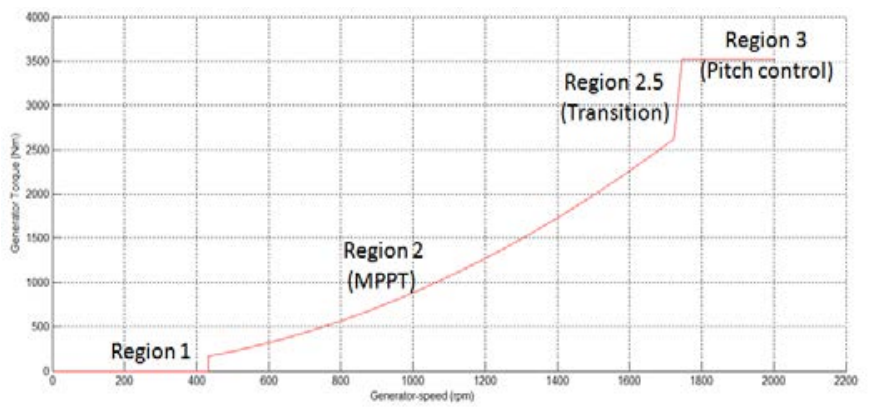

Fig. 2. Variable-speed turbine operating regions of the CART2 model

\section{CART2-PMSG Integrated Model}

In this work, the simplified generator in the CART2 model is fully replaced with a detailed PMSG and back-to-back average power converter to constitute a $600-\mathrm{kW}$ CART2PMSG integrated model [13]. In addition, the four-region operating scheme is fulfilled by the generator-side converter control so that this model represents the realistic operating characteristics of the original CART2 machine considering different wind speeds.

The generator-side converter can achieve the active and reactive power $(\mathrm{P} / \mathrm{Q})$ decoupling control using the rotor-fluxoriented control. Thus, the MPPT operation of the PMSGWTG is achieved by adjusting the generator electromagnetic power, $\mathrm{P}_{\text {ele }}$, to make the rotor speed run at the optimal power capture mode that corresponds to Region 2. By adopting the grid-voltage-oriented control for the $\mathrm{P} / \mathrm{Q}$ decoupling regulation, the grid-side converter (inverter) is able to maintain the DC-link voltage constant and ensure the unitypower-factor operation mode [14], [15]. The pitch angle control is implemented in an effort to keep the generator rotational speed at the rated value using the PI controller. The fundamental control structure of the CART2-PMSG integrated model is shown in Fig. 3. The values of the key parameters for the developed CART2-PMSG integrated model are summarized in Table 1.

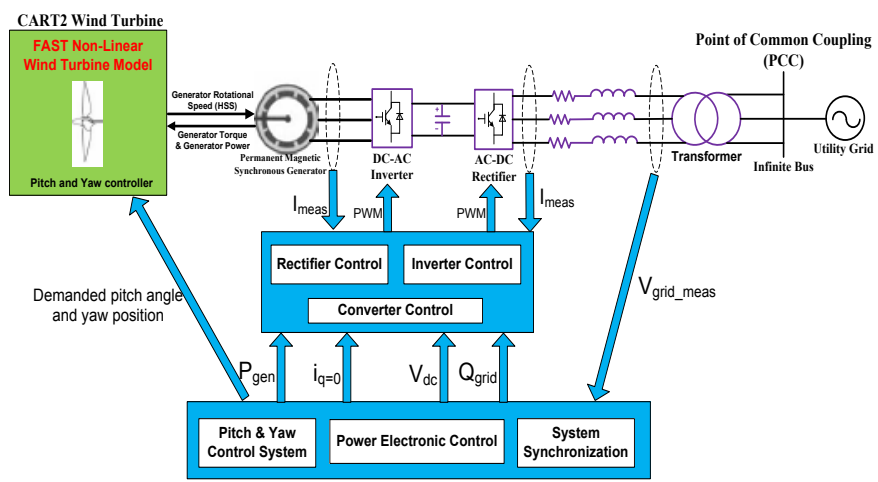

Fig. 3. Fundamental control structure of the CART2-PMSG integrated model

Table 1. List of CART2 Parameter Values

\begin{tabular}{|c|c|}
\hline$R$ (rotor radius) & $21.336 \mathrm{~m}$ \\
\hline$\rho$ (air density) & $1.03 \mathrm{~kg} / \mathrm{m} 3$ \\
\hline $\mathrm{C}_{\mathrm{p} \_ \text {max }}$ (the maximum power coefficient) & 0.396 \\
\hline$\lambda_{\text {opt }}$ (the optimum TSR) & 8.49 \\
\hline$\tau_{\text {rated_gen }}$ (generator rated torque) & $3524.4 \mathrm{~N}-\mathrm{m}$ \\
\hline$\omega_{\text {rated_gen }}$ (generator rated speed) & $1800 \mathrm{rpm}(188.5 \mathrm{rad} / \mathrm{s})$ \\
\hline$\omega_{\text {rated_wt }}$ (wind turbine rated speed) & $48.32 \mathrm{rpm}(5.06 \mathrm{rad} / \mathrm{s})$ \\
\hline $\mathrm{N}_{\text {gear }}$ (gearbox ratio) & 37.25 \\
\hline The pitch angle for $\mathrm{C}_{\text {pmax }}$ & -1 degree \\
\hline Rated wind speed (m/s) & 12.718 \\
\hline Rated mechanical power & $6 \mathrm{e} 5 \mathrm{~W}$ \\
\hline Rated apparent power & $664349.4 \mathrm{~W}$ \\
\hline Rated power factor & 0.903 \\
\hline
\end{tabular}

III. IMPROVED INERTIAL CONTROL METHOD OF PMSG-WTG

Fig. 4 shows a complete set of improved inertial control strategy, which is composed mainly of three sequential stages as highlighted in the red line: inertial response (Line A-B-C), temporary deloaded operation (Line C-D-E), and rotor speed recovery (Line E-A). The blue line represents the maximum power characteristics under different rotor speeds, and the black line indicates the mechanical power characteristics corresponding to a given wind speed and optimal pitch angle. The green line shows the electrical power reference that is in parallel with the maximum mechanical power curve by $\Delta \mathrm{P}$. During the inertial response, the kinetic energy stored in the rotating mass can be released by decelerating the rotor speed, 
$\omega_{\mathrm{WT}}$, because the electromagnetic torque is larger than the mechanical torque. The rotor speed declines along Line $\mathrm{B}-\mathrm{C}$ and eventually settles down at Point $\mathrm{C}$ due to the decreasing power imbalance. To achieve this function, the active power command $\mathrm{P}_{\text {ref_1 }}$ comprises a constant $\Delta \mathrm{P}$ and reference $\mathrm{P}_{\mathrm{MPPT}}$.

$$
\begin{array}{r}
\left(\mathrm{P}_{\text {MPPT }}=K \omega_{\mathrm{t}}{ }^{3}, \mathrm{k}=\frac{1}{2} \rho \pi \mathrm{R}^{5} \frac{\mathrm{C}_{\mathrm{pmax}}}{\left(\lambda_{\text {opt }}\right)^{3}}\right) . \\
\mathrm{P}_{\text {ref_1 }}=\mathrm{P}_{\text {MPPT }}+\Delta \mathrm{P}
\end{array}
$$

where $\mathrm{P}_{\text {MPPT }}$ is the maximum active power captured from the wind energy at a certain wind speed, $\Delta \mathrm{P}$ is a constant value in proportion to the rotor speed, $\omega_{\mathrm{WT}}$, which is a per-unit value based on the actual output power level instead of the wind turbine's rated power. It is more favorable to provide the stronger inertial response in the high rotor speed condition by setting a larger value of $\Delta \mathrm{P}$. On the other hand, a lower inertial response is still available for system frequency support in the low wind speed condition without causing the overdeceleration of the rotor speed. It is worth noting that the value of $\Delta \mathrm{P}$ cannot be set too high because the green line should intersect with or be tangent to the black line to assure the rotor speed stabilizes at the $\omega_{1}$. For the temporary deloaded operation, the active power command $\mathrm{P}_{\text {ref_2 }}$ is described as

$$
\mathrm{P}_{\text {ref_2 }}=\mathrm{P}^{*}-\Delta \mathrm{P}_{\mathrm{de}}
$$

where $\mathrm{P}^{*}$ is the active power value corresponding to the intersection Point $\mathrm{C}$ between the mechanical power curve and the electrical power curve, and $\Delta \mathrm{P}_{\mathrm{de}}$ is a constant value for the deloaded margin that drives the rotor speed to be accelerated due to the power imbalance. The larger the $\Delta \mathrm{P}_{\mathrm{de}}$ value is, the faster the rotor speed returns to the optimal Point $\mathrm{E}$, but the more likely a secondary frequency dip (SFD) occurs. So it is necessary to determine the appropriate value for $\Delta \mathrm{P}_{\mathrm{de}}$ to achieve a desirable trade-off between the recovery speed and frequency performance. Regarding the rotor speed recovery, the rotor speed can smoothly move toward the original Point A along Line E-A, and it finally settles down at Point A due to the decreasing power imbalance. At this stage, the active power command $\mathrm{P}_{\text {ref_3 }}$ remains constant as the optimal value:

$$
\mathrm{P}_{\text {ref_3 }}=\mathrm{P}_{\text {MPPT }}=\mathrm{K} \omega_{\mathrm{t}}^{3}
$$

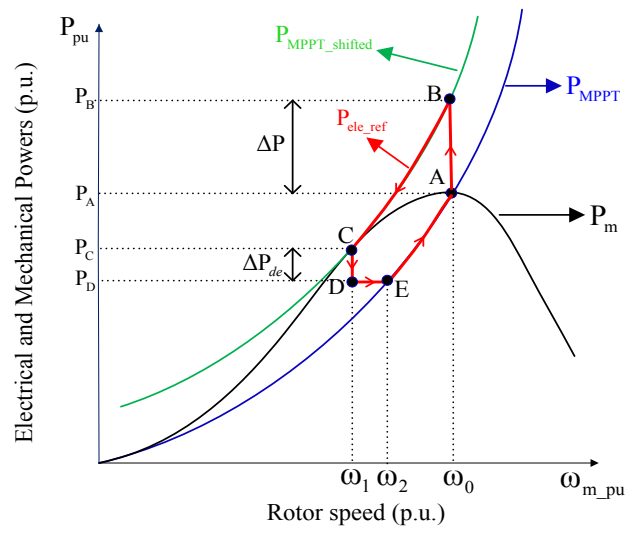

Fig. 4. Power-rotor speed trajectory

The specific control strategy of the inertial response implemented in MATLAB/Simulink is illustrated in Fig. 5. A disturbance detector is utilized to trigger the inertial response as the frequency deviation exceeds $0.02 \mathrm{~Hz}$ and sustains for a period of $100 \mathrm{~ms}$. When the rotor speed decreases to $\omega_{1}$ and the condition (4) is met for a specified period of time (1 s), in this case the rotor speed can basically reach the stable state and the frequency support is finished. At this moment, the power command is switched from the inertial response to temporary deloaded operation through the deloaded operation detector.

$$
\left|\omega_{\mathrm{t}}-\omega_{\mathrm{t}-1}\right| \leq 0.5 \times 10^{-3} \text { p.u. }
$$

where $\omega_{t}$ is the rotor speed at the moment $t(s)$ and $\omega_{t-1}$ is the rotor speed at the moment $\mathrm{t}-1$ (s). During the deloaded operation, the power command is changed to MPPT mode using the inertial recovery detector if the condition (5) is satisfied for a specified period of time $(50 \mathrm{~ms})$. This criterion can make sure that the active power output is able to increase from Point E moving along Line E-A without undergoing any possible decline.

$$
\omega_{\mathrm{t}} \geq \omega_{\mathrm{MPPT}}
$$

where $\omega_{\text {MPPT }}$ is the optimal rotor speed when WT operates at the deloaded power level, $\mathrm{P}_{\mathrm{D}}$. In other words, $\omega_{\mathrm{MPPT}}$ corresponds to the rotor speed $\omega_{2}$ at the point $\mathrm{E}$.

Note that the power magnitude limiter, torque magnitude limiter, and their rate limiters are added to this integrated model to avoid the excessive stress and overload imposed on the wind turbine's mechanical components (blade, drivetrain, and tower) when performing the inertial function.

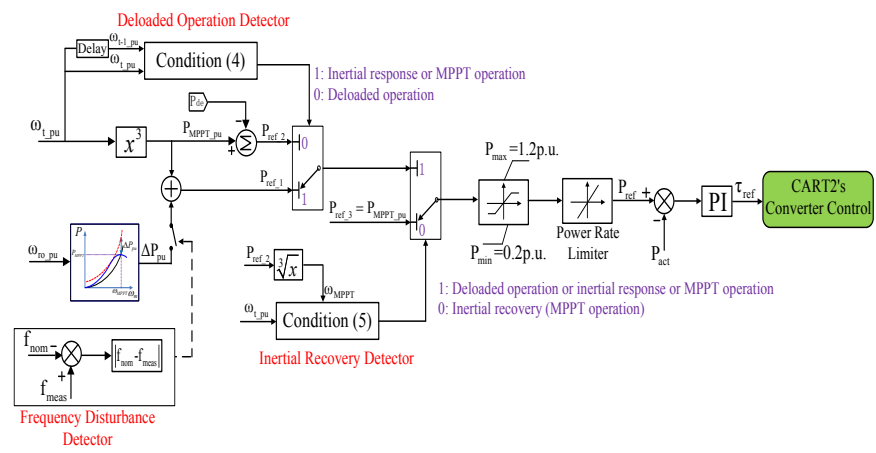

Fig. 5. Complete set of the improved inertial control scheme

\section{MOdEL SYSTEM AND CASE STUdY}

Fig. 6 shows a small power grid system consisting of three steam turbine generators and one CART2-PMSG WTG as established in MATLAB/Simulink. To simplify, the inertial time constant for the 12-MW SG1, 5-MW SG2, and 800-kW SG3 are uniformly set at $5 \mathrm{~s}$, and their droop coefficients are set to $5 \%$. The initial operating points for SG1 and SG2 are set to $0.8 \mathrm{p}$.u. of their rated capacities to allow for a certain power headroom to participate in the primary frequency regulation. The initial operating point of SG3 is set at 1 p.u., namely operating at the rated condition. Automatic generation control is disabled in this work, thus the steady-state error following the frequency disturbance remains.

At the moment of $30 \mathrm{~s}$, the generator rated $800 \mathrm{~kW}$ is tripped out of the grid and a rapid frequency decline immediately follows. To eliminate the influence of wind variation on the structural loads, CART2-PMSG operates in the constant wind speed of $10 \mathrm{~m} / \mathrm{s}$ wherein it is capable of 
providing 0.3 p.u. inertial response based on the current optimal power output. In this case, the performance of the proposed inertial scheme and its effect on the grid frequency is fully evaluated by comparing it to the case that uses no inertial control. Meanwhile, two different values of the deloaded margin, $\Delta \mathrm{P}_{\mathrm{de}}$, are chosen to explore its impact on the system frequency recovery process and structural loads of the wind turbine. Therefore, a series of results regarding the grid side, electrical and mechanical features as well as the selected loading variables are made available in three scenarios. The black line is the basic case without the wind turbine's inertial response. The blue line represents the proposed inertial response with $\Delta \mathrm{P}_{\mathrm{de}}=0.03$ p.u., and the red line shows the proposed inertial response with $\Delta \mathrm{P}_{\mathrm{de}}=0.0044$ p.u.

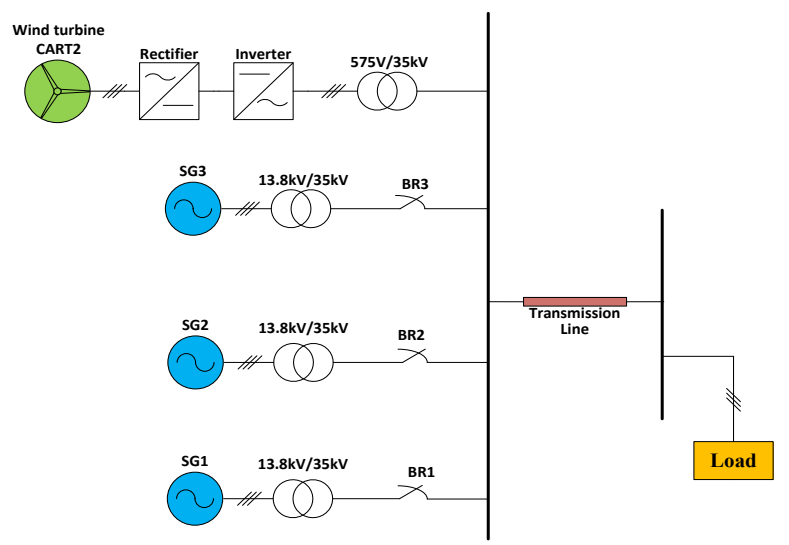

Fig. 6. Basic configuration of a small-scale power grid system

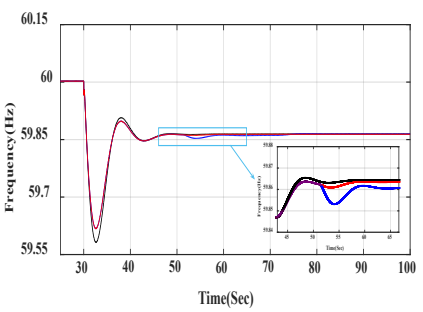

(a) System frequency $(\mathrm{Hz})$

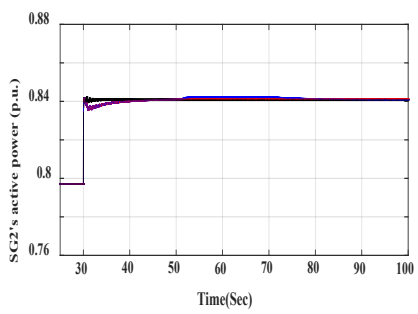

(c) Active power output of SG2 (p.u.)

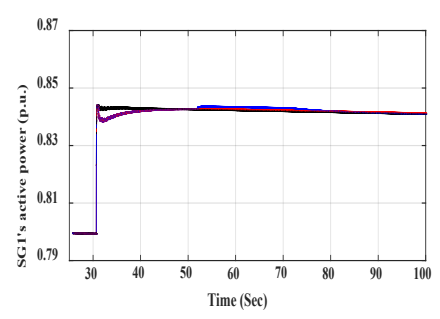

(b) Active power output of SG1 (p.u.)

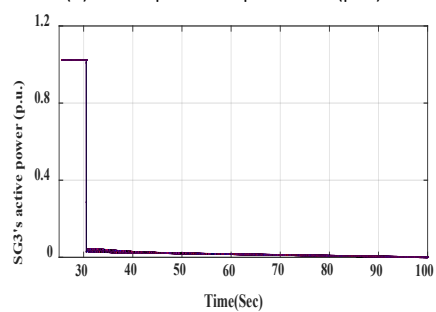

(d) Active power output of SG3 (p.u.)

Fig. 7. Simulation results from the grid side

As shown in Fig. 7 and Fig. 8, as the frequency disturbance occurs at $30 \mathrm{~s}$, the inertial response is activated to increase the electrical power to compensate for the power deficit caused by the SG3 trip. With the proposed inertial response, the kinetic energy stored in the rotating mass of the wind turbine is rapidly released and injected into the grid through the power converter control. As a result, the overall frequency performance is significantly improved in terms of ROCOF, frequency nadir, and its recovery process, as shown in Table 2.
Meanwhile, the risk of load disconnection triggered by the under-frequency load-shedding protection (UFLS) scheme is reduced. The active power output of PMSG-WTG temporarily rises due to the increased power reference value and then smoothly decreases with time until the rotor speed reaches the steady state at $50 \mathrm{~s}$. During this process, more response time is allowed for the online SG1 and SG2 that have slow ramp rates to respond and carry out the primary frequency regulation after the inertial response. Accordingly, the duration of the overloading operation for these two synchronous generators is shortened.
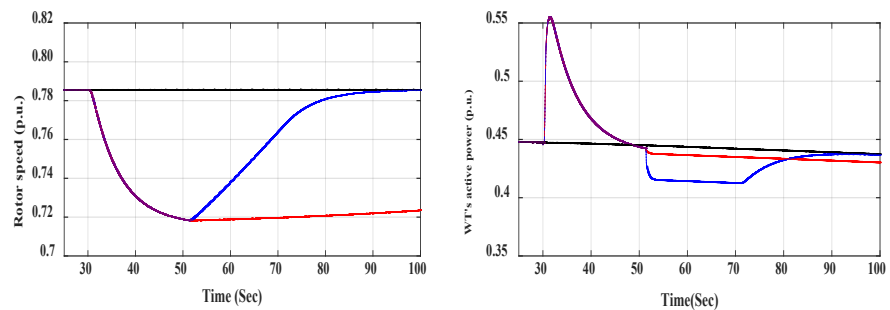

(a) Generator rotor speed (p.u.)

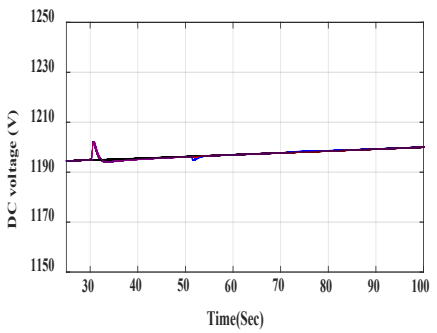

(c) DC-link voltage (V)

(b) Active power output (p.u.)

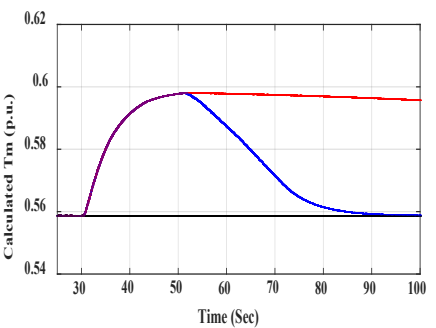

(d) Calculated mechanical torques (p.u.)

Fig. 8. Simulation results from the PMSG model

Table 2. Comparison of System Frequency Characteristics

\begin{tabular}{|c|c|c|c|c|}
\hline Control Method & $\begin{array}{c}\text { ROCOF } \\
(\mathrm{Hz} / \mathrm{s})\end{array}$ & $\begin{array}{c}\text { Frequency } \\
\text { Nadir } \\
(\mathrm{Hz})\end{array}$ & $\begin{array}{c}\text { Duration to } \\
\text { Reach the } \\
\text { Secondary } \\
\text { Steady State (s) }\end{array}$ & $\begin{array}{c}\text { Frequency } \\
\text { Overshoot } \\
(\mathrm{Hz})\end{array}$ \\
\hline $\begin{array}{c}\text { No Inertial } \\
\text { Response }\end{array}$ & -0.167 & 59.58 & 46.8 & 59.91 \\
\hline $\begin{array}{c}\text { Proposed } \\
\text { Inertial } \\
\text { Response }\end{array}$ & -0.149 & 59.62 & 46.8 & 59.9 \\
\hline
\end{tabular}

Meanwhile, the rotor speed begins to decline as a result of the mechanical and electrical torque imbalance, and eventually it arrives at the secondary steady state, where the torque balance is reestablished. According to the lookup table about the power coefficient $\mathrm{C}_{\mathrm{p}}$ versus TSR under a certain pitch angle, it is observed that the calculated mechanical torque gradually rises until it reaches toward the steady value equal to the electrical torque. That is because the rotor speed, $\omega_{0}$, corresponding to the MPPT power at Point A is higher than the counterpart corresponding to the maximum torque under a constant wind speed condition. As a result, the new steadystate torque is larger than the previous steady torque since the rotor speed gradually decreases. The DC link voltage is well maintained constant at a rated value of $1,200 \mathrm{~V}$ during the entire inertial response. Regarding the deloaded operation with different deloaded margins, the wind turbine with the $\Delta \mathrm{P}_{\mathrm{de}}$ of 0.03 p.u. can accelerate toward $\omega_{2}$ and enter MPPT mode much faster than the case with the $\Delta \mathrm{P}_{\mathrm{de}}$ of 0.004 p.u., as 
shown in Fig. 7(a). So the larger $\Delta \mathrm{P}_{\mathrm{de}}$ can make a quicker recovery of the rotor speed, whereas the more severe SFD occurs as shown in the enlarged image of Fig. 7 (a). Thus, a small $\Delta \mathrm{P}_{\mathrm{de}}$ is preferred from the perspective of improving the frequency stability.

In Fig. 9, there are no noticeable impacts on the tower and blade stress because of this sudden increase in electrical power. Actually, Blade 1's out-of-plane shear force and flapwise shear force as well as tower base fore-aft shear force tend to become slightly smaller during the inertial response stage. This is mainly because the decreasing rotor speed leads to decreasing TSR and likely decreasing thrust [16] Therefore, the implementation of the proposed inertial control scheme in Region 2 does not adversely impact the mechanical components between the blades and the generator and thus is unlikely to jeopardize the wind turbine's lifetime.
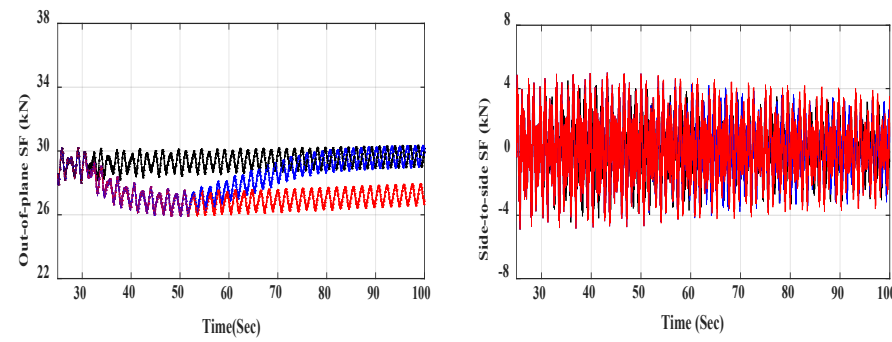

(a) Blade 1 out-of-plane shear force (kN)

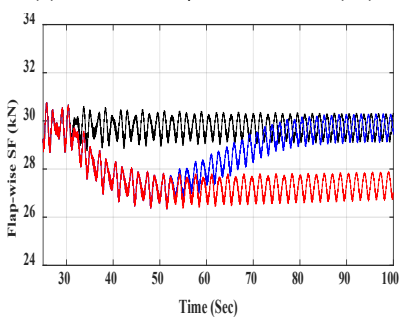

(c) Blade 1 flap-wise shear force (kN)

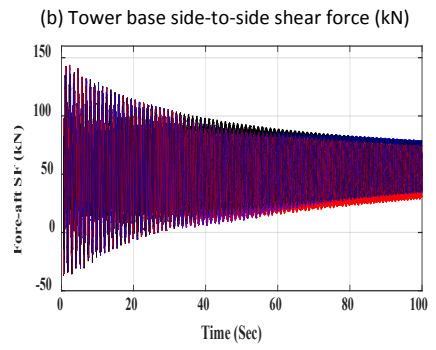

(d) Tower base fore-aft shear force ( $\mathrm{kN}$ )

Fig. 9. Simulation results from the FAST-based CART2 model

\section{CONCLUSION}

In this paper, an improved inertial control method based on the MPPT characteristic is presented for the purpose of enhancing the frequency regulation capability of PMSGWTGs without additional power reserve. To illustrate its effectiveness, an integrated CART2-PMSG model equipped with the proposed inertial control is established in MATLAB/Simulink, and its frequency regulation performance is evaluated in the event of a single generator loss. Simulation results demonstrate that the improved inertial control enables the PMSG-WTG to arrest the ROCOF and improve the frequency nadir, whereas the proper deloaded value can avoid an SFD throughout the rotor speed recovery process. Moreover, the application of the improved inertial control into the PMSG-WTG cannot cause any potential damage to the wind turbine's mechanical components when it is operating at a certain wind speed.

Future work is planned to implement the proposed inertial control method into the real CART2 machine at the NWTC to validate the actual impact on the extreme loads and fatigue loads of a wind turbine when executing this inertial response. Meanwhile, the maximum value of $\Delta \mathrm{P}$ corresponding to different wind speeds will be further studied to ensure that the PMSG-WTG is capable of fulfilling the optimum frequency support under various and continuous wind conditions during any grid frequency event.

\section{ACKNOWLEDGMENTS}

This work was supported by the U.S. Department of Energy under Contract No. DE-AC36-08-GO28308 with the National Renewable Energy Laboratory. The authors wish to acknowledge the support provided by Paul Fleming and Andrew Scholbrock of NREL during the preparation of this paper and the future implementation on the CART turbine.

\section{REFERENCES}

[1] Y. Liu, J. Gracia, T. King, and Y. Liu, "Frequency regulation and oscillation damping contriubtions of variable-speed wind generators in the U.S. eastern interconnection (EI)," IEEE Trans. Sustain. Energy, vol. 6, no. 99 , pp. 1-8, 2015.

[2] I. A. Gowaid, A. El-Zawawi, and M. El-Gammal, "Improved inertia and frequency support from grid-connected DFIG wind farms," in Proc. 2011 IEEE Power Systems Conference and Exposition, pp. 1-9.

[3] Z. Wu, W. Gao, J. Wang, and S. Gu, "A coordinated primary frequency regulation from permanent magnet synchronous wind Turbine generation," IEEE Power Electronics and Machines in Wind Applications, pp. 1-6, 2012.

[4] R. You, B. Barahona, J. Chai et al., "Frequency support capability of variable speed wind turbine based on electromagnetic coupler," Renewable Energy, vol. 74, pp. 681-688, 2015.

[5] E. Muljadi, V. Gevorgian, M. Singh, and S. Santoso, "Understanding inertial and frequency response of wind power plants," IEEE Power Electronics and Machines in Wind Applications, pp. 1-8, 2012.

[6] Y. Wang, G. Delille, H. Bayem, X. Guillaud, and B. Francois, "High wind power penetration in isolated power systems - Assessment of wind inertial and primary frequency responses," IEEE Trans. Power Syst., vol. 28, no. 3, pp. 2,412-2,420, 2013.

[7] G. C. Tarnowski, P. C. Kjar, P. E. Sorensen, and J. Ostergaard, "Variable speed wind turbines capability for temporary over-production," in Proc. 2009 IEEE Power \& Energy Society General Meeting, pp. 1-7.

[8] Y. Yang, J. Meng, X. Zhang et al., "Control of PMSG-based wind turbines for sytem inertial response and power oscilallation damping," IEEE Trans. Sustain. Energy, vol. 6, no. 2, pp. 565-574, 2015.

[9] A. D. Wright and L. J. Fingersh, "Advanced control design for wind turbines-Part I: Control design, implementation, and initial tests," National Renewable Energy Laboratory, Golden, CO, Tech. Rep., NREL/TP-500-42437, March, 2008.

[10] J.M. Jonkman and M. L. Buhl Jr., "FAST user's guide," National Renewable Energy Laboratory, Golden, CO, Tech. Rep., NRL-EL-50038230, August, 2005.

[11] B. Wu, Y. Lnag et al., Power Conversion and Control of Wind Energy Systems. New York: Wiley, 2011.

[12] T. Ackermann, Wind Power in Power Systems, 2nd ed. New York: Wiley, 2012.

[13] M.Singh, E.Muljadi, J. Jonkman et al., "Simulation for wind turbine generators-with FAST and MATLAB-simulink modules," National Renewable Energy Laboratory, Golden, CO, Tech. Rep., NREL/TP5D00-59195, April, 2014.

[14] A. Rolan, A. Luna, G. Vazquez et al., "Modeling of a variable speed wind turbine with a permanent magnet synchronous generator," in Proc. 2009 IEEE International Symposium on Industrial Electronics, pp. 734 739, Seoul, Korea, July 5-8.

[15] A. M.Hemeida, W. A.Frag, and O. A. Mahgoub, "Modelling and control of direct driven PMSG for ultra large wind turbines," World Academy of Science, Engineering and Technology, vol. 5, Nov. 2011.

[16] P. A. Fleming, J. Aho, A. Buckspan et al., "Effects of power reserve control on wind turbine structural loading," Wind Energy, 2015. 